\title{
Psoriatic arthritis and imaging
}

\author{
P A Ory, D D Gladman, P J Mease
}

Ann Rheum Dis 2005;64(Suppl II):ii55-ii57. doi: 10.1136/ard.2004.033928

Psoriatic arthritis ( $\mathrm{Ps} A$ ) has historically been considered a milder rheumatic disease not yielding significant clinical damage. However, recent studies have shown that PsA can be deforming and debilitating and that joint damage can be severe. Traditionally, joint damage has been recorded using plain radiographs. Characteristic radiographic features of PsA include joint erosions, joint space narrowing, bony proliferation including periarticular and shaft periostitis, osteolysis including "pencil in cup" deformity and acroosteolysis, ankylosis, spur formation, and spondylitis. New imaging modalities, including ultrasound, bone scanning, and magnetic resonance imaging may help in both diagnosis and follow up of patients with PsA. These new imaging techniques will with validation help detect early changes in the peripheral joints, the periarticular tissues, and the spinal structures in patients with PsA.

$\mathrm{P}$ soriatic arthritis (PsA) has historically been considered a milder rheumatic disease not yielding significant clinical damage. However, recent studies have shown that PsA can be deforming and debilitating and that joint damage can be severe. ${ }^{12}$ In a study of 220 patients with PsA, Gladman et al found deformity, radiological damage, or both, in more than five joints in about $16 \%$ of the patients. Approximately $67 \%$ of the patients had erosive joint disease. ${ }^{2}$ Although there may be clinical improvement after treatment with antiinflammatory agents, there is progressive joint damage as measured by radiographic changes. ${ }^{3}$ As discussed in the article on treatment of PsA with biological response modifiers elsewhere in this supplement, ${ }^{5}$ it is now known that anti-TNF therapy can substantially inhibit joint destruction as measured radiographically. Thus, it is important to be able to assess joint damage accurately by radiographic and other imaging techniques in order to intervene with appropriate therapy. Further, a need for reliable imaging approaches arises when trying to establish a diagnosis of PsA, in order to distinguish it from other arthritides, as well as to help establish extent of disease. The radiographic features of PsA and role of imaging modalities other than $x$ ray are reviewed here. Specific methods for radiographic assessment of joints, particularly in the context of clinical trials, are reviewed in this supplement by van der Heijde et al. ${ }^{6}$ The reader is also referred to other recent reviews of imaging in rheumatic disease $^{78}$ and spondyloarthropathy. ${ }^{9}$

\section{RADIOGRAPHIC FEATURES OF PsA}

Characteristic radiographic features of PsA include joint erosions, joint space narrowing, bony proliferation including periarticular and shaft periostitis, osteolysis including "pencil in cup" deformity and acro-osteolysis, ankylosis, spur formation, and spondylitis. ${ }^{10}$ Unlike rheumatoid arthritis (RA), joint involvement in PsA is often asymmetrical and may be oligoarticular; osteoporosis is atypical. Although erosive changes in early PsA are marginal as in RA, they become irregular and ill defined with disease progression because of periosteal bone formation adjacent to the erosions. In severe cases, erosive changes may progress to development of pencil in cup deformity or gross osteolysis. ${ }^{11}{ }^{12}$ These features are typical of arthritis mutilans. Asymmetrical erosions may be visible radiographically in the carpus and in the metacarpophalangeal (MCP), proximal interphalangeal (PIP), and distal interphalangeal (DIP) joints of the hands, but the DIP joints are often the first to be affected. Abnormalities are seen in the phalangeal tufts and at the sites of attachments of tendons and ligaments to the bone. The presence of DIP erosive changes may provide both sensitive and specific radiographic findings to support the diagnosis of PsA. Also, the hands tend to be involved much more frequently than the feet with a ratio of nearly $2: 1 .{ }^{1}$

Erosive changes and bone proliferation in the feet usually involve the interphalangeal and metatarsophalangeal joints; the interphalangeal joint of the great toe is most often affected. Periosteal and endosteal bone formation may increase the radiodensity of an entire phalanx, and if significant bony proliferation occurs, an "ivory" phalanx may result. This finding is a unique and specific radiographic manifestation of PsA, but it is uncommon; thus, sensitivity for this finding is low. However, it is of particular importance when articular abnormality or resorption of the tufts is absent. ${ }^{12}$ Other features typical of PsA are soft tissue swelling of entire digits due to dactylitis and ankylosis.

Spondylitis is a characteristic feature of PsA and may be difficult to distinguish from ankylosing spondylitis radiologically. Syndesmophytes (bony outgrowths) occur in both PsA and ankylosing spondylitis, but in PsA they may be paramarginal and do not appear in consecutive vertebrae. Erosions occur on the surface of the vertebrae, and syndesmophytes form at the site of the erosion or in adjacent soft tissue. Other characteristics of spondylitic PsA are atlantoaxial subluxation, apophyseal joint ankylosis, and ligamentous calcification. ${ }^{10}{ }^{13}{ }^{14}$ Sacroiliitis has been documented in approximately a quarter of PsA patients in two series, $^{215}$ yet in a third series of 221 patients reported by Clegg and colleagues, ${ }^{16}$ it was noted in $78 \%$. Often, the sacroiliac involvement is unilateral. Patients who have PsA with axial (spondylitic) changes and peripheral arthritic involvement may have more frequent and more severe joint lesions, as shown in a study by Taccari et al. ${ }^{17}$

\section{ULTRASONOGRAPHY}

Musculoskeletal ultrasound has been used for several years to assess joint pathology and may have utility in assessing disease activity in patients with inflammatory joint disease including PsA. ${ }^{18}$ The use of high frequency transducers (10 $\mathrm{MHz}$ or more) provides excellent tissue resolution. Ultrasound can be used to assess synovial tissue, joint effusions, erosions, and in conjunction with Doppler interrogation, a qualitative measure of hyperaemia, which may be

Abbreviations: $\operatorname{Ps} A$, psoriatic arthritis; $R A$, rheumatoid arthritis 
an indirect sign of inflammation. ${ }^{19}$ Doppler may also be an important tool in assessing tenosynovitis and more specific features of PsA such as enthesitis. ${ }^{20}$ Enthesitis at Achilles' tendon is identified by ultrasonography in a much higher frequency than on clinical examination in patients with psoriasis and PsA. ${ }^{21}$ However, the sonographic findings are non-specific, as they may occur in patients with osteoarthritis and RA as well as in patients with PsA. ${ }^{22}$ It will therefore be important to correlate these qualitative features with histopathology. Ultrasonography may be a useful tool in the assessment of dactylitis. ${ }^{23}$

\section{SCINTIGRAPHY}

Bone scintigraphy has been used widely in the past, but is now being supplanted with ultrasound and magnetic resonance imaging (MRI) techniques. It has been somewhat useful in detecting inflammatory changes, especially in situations where the radiograph is normal. However, it lacks specificity. ${ }^{9}$ Occasionally sacroiliitis and entheseal inflammation can be identified with scintigraphy.

\section{COMPUTED TOMOGRAPHY}

Computed tomography (CT) may be useful in assessing elements of spine disease, but has little role in assessment of peripheral joints. It has been shown to be similarly accurate in assessment of erosions in sacroiliac joints when compared to MRI but is not as effective in distinguishing synovial inflammation. ${ }^{94}$ It also may be used to help guide sacroiliac joint injection.

\section{MRI}

Structural damage has been a major outcome measure in patients with RA and PsA and has traditionally been measured using scoring methods applied to plain film radiography. An international Outcome Measures in Rheumatology Clinical Trials (OMERACT) MRI in RA working group has been developing a scoring system to assess synovitis, bone oedema, and erosions in hands and wrists that would satisfy the OMERACT filter. ${ }^{25}$ Since patients with PsA share many of the same clinical features as patients with RA, this MRI scoring system might also be a potential outcome measure in patients with PsA. MRI may have the advantage of detecting some of these features earlier than plain radiography. This is important in that response to treatment and disease activity may be measured before structural damage occurs. ${ }^{26}{ }^{27}$ MRI was recently used to measure synovial vascularity in the RA wrist following initiation of therapy, ${ }^{28}$ an approach that is currently being employed in a current PsA trial with antitumour necrosis factor (anti-TNF) therapy (P Mease, personal communication).

In a study of infliximab in PsA, MRI was used to detect changes in inflammatory activity as measured by a significant reduction in gadolinium uptake following treatment. ${ }^{27}$ However, similar to ultrasound, since some of these measured features are non-specific, it will be important to obtain histopathological correlation whenever feasible and to enrol patients in longitudinal studies to validate this modality as an outcome measure of disease.

We conclude that, in addition to plain radiographs, these new imaging techniques with validation will help detect early changes in the peripheral joints, the periarticular tissues, and the spinal structures in patients with psoriatic arthritis.

\section{Authors' affiliations \\ P A Ory, University of Washington, Seattle, WA and Highline Community Hospital, Burien, WA, USA}

D D Gladman, Toronto Western Research Institute, Psoriatic Arthritis Program, University Health Network, Centre for Prognosis Studies in the Rheumatic Diseases, Toronto Western Hospital, Toronto, Ontario, Canada

P J Mease, Seattle Rheumatology Associates and Swedish Medical Center Rheumatology Research Division, University of Washington School of Medicine Seattle, WA, USA

Correspondence to: Dr D Gladman, Toronto Western Research Institute, Psoriatic Arthritis Program, University Health Network, Centre for Prognosis Studies in the Rheumatic Diseases, Toronto Western Hospital, 399 Bathurst St. ECW 5-034B, Toronto, Ontario, M5T 2S8, Canada; dafna.gladman@utoronto.ca

\section{REFERENCES}

1 Rahman P, Nguyen E, Cheung C, Schentag CT, Gladman DD. Comparison of radiological severity in psoriatic arthritis and rheumatoid arthritis. J Rheumatol 2001;28:1041-4.

2 Gladman DD, Shuckett R, Russell ML, Thorne JC, Schachter RK. Psoriatic arthritis (PsA) - an analysis of 220 patients. Q J Med 1987:62:127-41.

3 Gladman DD, Stafford-Brady F, Chang CH, Lewandowski K, Russell ML. Longitudinal study of clinical and radiological progression in psoriatic arthritis. J Rheumatol 1990;17:809-12.

4 Hanly JG, Russell ML, Gladman DD. Psoriatic spondyloarthropathy: a long term prospective study. Ann Rheum Dis 1988;47:386-93.

5 Mease PJ, Antoni CE. Psoriatic arthritis treatment: biological response modifiers. Ann Rheum Dis 2005;64(suppl II):ii78-82.

6 van der Heijde D, Sharp J, Wassenberg S, Gladman DD. Psoriatic arthritis imaging: a review of scoring methods. Ann Rheum Dis 2005;64(suppl II):ii61-4.

7 Ory PA. Radiography in the assessment of musculoskeletal conditions. Best Pract Res Clin Rheumatol 2003;17:495-512.

8 Wakefield RJ, Conaghan PG, Jarrett S, Emery P. Noninvasive techniques for assessing skeletal changes in inflammatory arthritis: Imaging technique. Curr Opin Rheumatol 2004;16:435-42.

9 Grigoryan M, Roemer FW, Mohr A, Genant HK. Imaging in spondyloarthropathies. Curr Rheumatol Rep 2004:6:102-9.

10 Wassenberg S, Fischer-Kahle V, Herborn G, Rau R. A method to score radiographic change in psoriatic arthritis. $Z$ Rheumatol $2001 ; 60: 156-66$.

11 Gold RH, Bassett LW, Seeger LL. The other arthritides. Roentgenologic features of osteoarthritis, erosive osteoarthritis, ankylosing spondylitis, psoriatic arthritis, Reiter's disease, multicentric reticulohistiocytosis, and progressive systemic sclerosis. Radiol Clin North Am 1988;26:1195-212.

12 Resnick D, Broderick TW. Bony proliferation of terminal toe phalanges in psoriasis: the "ivory" phalanx. J Can Assoc Radiol 1977;28:187-9.

13 Salvarani C, Macchioni P, Cremonesi T, Mantovani W, Battistel B, Rossi F, et al. The cervical spine in patients with psoriatic arthritis: a clinical, radiological and immunogenetic study. Ann Rheum Dis 1992;51:73-7.

14 Laiho K, Kauppi M. The cervical spine in patients with psoriatic arthritis. Ann Rheum Dis 2002;61:650-2.

15 Torre Alonso JC, Rodriguez Perez A, Arribas Castrillo JM, Ballina Garcia J, Riestra Noriega JL, et al. Psoriatic arthritis (PA): a clinical, immunological and radiological study. Br J Rheumatol 1991;30:245-50

16 Battistone MJ, Manaster BJ, Reda DJ, Clegg DO. The prevalence of sacroiliitis in psoriatic arthritis: new perspectives from a large, multicenter cohort. A Department of Veterans Affairs Cooperative Study. Skeletal Radiol 1999;28:196-201.

17 Taccari E, Spadaro A, Riccieri V. Correlations between peripheral and axial radiological changes in patients with psoriatic polyarthritis. Rev Rhum English Ed 1996;63:17-23.

18 Swen WA, Jacobs JW, Algra PR, Manoliu RA, Rijkmans J, Willems WJ, et al. Sonography and MRI imaging equivalent for the assessment of full thickness rotator cuff tears. Arthritis Rheum 1999;42:2231-8.

19 Wakefield RJ, Gibbon WW, Conaghan PG, O'Connor P, McGonagle D, Pease $C$, et al. The value of sonography in the detection of bone erosions in patients with rheumatoid arthritis: a comparison with conventional radiography. Arthritis Rheum 2000;43:2762-70.

20 D'Agostino MA, Said-Nahal R, Hacquard-Bouder C, Brasseur JL, Dougados M, Breban M. Assessment of peripheral enthesitis in spondylarthropathies by ultrasonography combined with power Doppler: a cross-sectional study. Arthritis Rheum 2003;48:523-33.

21 De Simone C, Guerriero C, Giampetruzzi AR, Costantini M, Di Gregorio F, Amerio $P$, et al. Achilles tendinitis in psoriasis: clinical and sonographic findings. J Am Acad Dermatol 2003;49:217-22.

22 Falsetti P, Frediani B, Fioravanti A, Acciai C, Baldi F, Filippou G, et al. Sonographic study of calcaneal entheses in erosive osteoarthritis, nodal osteoarthritis, rheumatoid arthritis and psoriatic arthritis. Scand J Rheumatol 2003;32:229-34.

23 Kane D, Greaney T, Bresnihan B, Gibney R, FitzGerald O. Ultrasonography in the diagnosis and management of psoriatic dactylitis. J Rheumatol 1999;26:1746-51.

24 Puhakka KB, Jurik AG, Egund N, Schiottz-Christensen B, StengaardPedersen K, van Overeem Hansen $G$, et al. Imaging of sacroiliitis in early seronegative spondylarthropathy. Assessment of abnormalities by MR in comparison with radiography and CT. Acta Radiol 2003;44:218-29.

25 Ostergaard M, Peterfy C, Conaghan P, McQueen F, Bird P, Ejbjerg B, et al. OMERACT rheumatoid arthritis magnetic resonance imaging studies. Core set 
of MRI acquisitions, joint pathology definitions, and the OMERACT RA-MRI scoring system. J Rheumatol 2003;30:1385-6, Erratum in: J Rheumatol, 2004:31:198.

26 McQueen FM, Benton N, Crabbe J Robinson E, Yeoman S, Mclean $\mathrm{L}$, et al. What is the fate of erosions in early rheumatoid arthritis? Tracking individual lesions using $x$-rays and magnetic resonance imaging over the first two years of disease. Ann Rheum Dis $2001 ; 60: 859-68$
27 Antoni C, Dechant C, Hanns-Martin Lorenz PD, Wendler J, Ogilvie A, Lueft M, et al. Open-label study of infliximab treatment for psoriatic arthritis: clinical and magnetic resonance imaging measurements of reduction of inflammation. Arthritis Rheum 2002:47:506-12.

28 Gardner J, Zierhut M, Gardner G, Mease P, Sharpe J. Changes in MRI measures of synovial vascularity in the RA wrist at 1-2 months following initiation of anti-TNF $\alpha$ and methotrexate therapy. Arthritis Rheum 2003;48:S131. 